\title{
Polygenic Risk Scores for Psychiatric Disorders Reveal Novel Clues About the Genetics of Disordered Gambling
}

\author{
Thomas M. Piasecki, Ian R. Gizer, and Wendy S. Slutske \\ Department of Psychological Sciences \\ University of Missouri, Columbia, MO
}

Running Head: Polygenic Risk and Disordered Gambling

Keywords: gambling, schizophrenia, polygenic risk score, comorbidity

Word Count: 3,712

\section{Correspondence to:}

Thomas M. Piasecki, Ph.D., Department of Psychological Sciences, University of Missouri, 210 McAlester Hall, Columbia, MO 65211. Phone: 573-882-8877. Email: piaseckit@missouri.edu 


\begin{abstract}
Disordered gambling (DG) is a rare but serious condition that results in considerable financial and interpersonal harms. Twin studies indicate that DG is heritable but are silent with respect to specific genes or pathways involved. Existing genome-wide association studies (GWAS) of DG have been substantially underpowered. Larger GWAS of other psychiatric disorders now permit calculation of polygenic risk scores (PRS) that reflect the aggregated effects of common genetic variants contributing risk for the target condition. The current study investigated whether gambling and DG are associated with PRSs for four psychiatric conditions found to be comorbid with DG in epidemiologic surveys: major depression (MDD), attentiondeficit hyperactivity disorder (ADHD), bipolar disorder (BD), and schizophrenia (SCZ). Genotype data and survey responses were analyzed from the Wave IV assessment (conducted in 2008) of the National Longitudinal Study of Adolescent to Adult Health, a representative sample of adolescents recruited in 1994-5 and followed into adulthood. Among participants classified as having European ancestry based on genetic analysis $(N=5,215), 78.4 \%$ reported ever having gambled, and $1.3 \%$ reported lifetime DG. Polygenic risk for BD was associated with decreased odds of lifetime gambling, $\mathrm{OR}=0.93[0.87,0.99], p=.045$, pseudo- $R^{2}(\%)=.12$. The SCZ PRS was associated with increased odds of $\mathrm{DG}, \mathrm{OR}=1.54[1.07,2.21], p=.02$, pseudo- $R^{2}(\%)=.85$. Polygenic risk for MDD and ADHD were not related to either gambling outcome. Investigating features common to both SCZ and DG might generate valuable clues about the geneticallyinfluenced liabilities to DG.
\end{abstract}


For many, gambling is a form of entertainment, but a subset of individuals progresses to develop a pattern of disordered gambling (DG) characterized by difficulty controlling gambling behavior, chasing losses, and serious financial and interpersonal hardships (Hodgins, et al., 2011; Li, et al., 2017). Surveys of nationally-representative U.S. samples estimate that approximately $2.3 \%$ of adults experience at least one lifetime symptom of gambling disorder (Kessler, et al., 2008 ) and that the lifetime prevalence of diagnosable DG among adults is between 0.4 to $0.6 \%$ (Kessler, et al., 2008; Petry, et al., 2005).

Twin studies have established that DG is heritable, with additive genetic influences accounting for between 40 to $80 \%$ of the phenotypic variance in samples of adults and 5 to $20 \%$ of the variance in adolescents and young adults (Slutske, 2019). Classical twin studies provide an estimate of the aggregated effect of genes, but are silent with respect to the specific genes or biological pathways that may be involved in the disorder.

Starting from theory and empirical clues about possible neural mechanisms implicated in dysregulated gambling and related traits, researchers have tested associations between DG and a variety of functional candidate genes (Nautiyal, et al., 2017; Slutske, 2019). These efforts have not yet identified strong and consistent associations between selected variants and DG. Accumulating experience with large-scale, hypothesis-free genome-wide association studies (GWAS) casts doubt on the utility of the candidate gene approach. The top GWAS hits for psychiatric traits frequently arise in unexpected genomic regions and implicate biological pathways unanticipated by prevailing etiologic theory, suggesting our intuitions about candidate genes may not be adequate for steering inquiry into the genetic determinants of disorders (Sullivan, et al., 2018). 
To date, there have been two GWAS of DG including a total of only 2,742 participants, with no genome-wide significant single nucleotide polymorphisms (SNPs) or genes detected in either study (Lang, et al., 2016; Lind, et al., 2012). Available evidence from GWAS involving other psychiatric conditions indicate that these disorders most likely arise from the combined influence of a large number of common variants, each of which has a small effect (Sullivan, et al., 2018). Practically, this requires very large sample sizes to identify associated variants at a genome-wide level of statistical significance. GWAS may yet make important contributions to elucidating the genetic underpinnings of DG, but this will require concerted efforts to amass much larger samples.

Epidemiologic studies indicate that DG is comorbid with numerous other psychiatric conditions (Edens \& Rosenheck, 2012; Kessler, et al., 2008; Petry, et al., 2005). Investigating the extent to which these comorbidity patterns are attributable to overlapping genetic influences could provide valuable clues concerning the biological bases of DG. Multivariate twin studies have produced evidence for genetic correlations between DG and substance use disorders (Slutske, e al., 2000; Slutske, et al., 2013; Xian, et al., 2014), antisocial behaviors (Slutske, et al., 2001), and obsessive-compulsive disorder features (Scherrer, et al., 2015). Existing studies of DG and major depression have yielded mixed findings (Blanco, et al., 2012; Potenza, et al., 2005). Fitting joint twin models is tractable when studying overlap between DG and common mental disorders. However, because DG is itself fairly rare, sparse data often prevent meaningful twin analyses of genetic overlap between DG and less prevalent conditions. This may effectively limit what can be learned about genetic causes of comorbidity from biometric models using twin samples. 
Although gambling research lags behind, a number of large-scale collaborative efforts have now been organized to conduct powerful GWAS investigations of several psychiatric disorders (Sullivan, et al., 2018). This has generated new tools - polygenic risk scores (PRSs) that can be leveraged to investigate the genetic bases of psychiatric disorders (Bogdan, et al., 2018; Dudbridge, 2016; Maier, et al., 2018). A PRS is constructed by applying regression weights derived from a target GWAS to genotype data collected from an independent sample, yielding a single summary score for each individual estimating their level of risk for the target disorder based on the aggregated effects of their common genetic variants. PRSs provide a method for examining how the phenotypic expression of an understudied disorder, such as DG, relates to common variant risk for other psychiatric disorders, including comparatively rare conditions that have been examined in large case-control GWASs.

The current study examines associations between DG and PRSs for four psychiatric conditions - attention deficit/hyperactivity disorder (ADHD), major depressive disorder (MDD), bipolar disorder (BD), and schizophrenia (SCZ) - in a nationally-representative sample of young adults from the United States. Each of these disorders overlaps with DG at the phenotypic level in epidemiological samples (Clark, et al., 2013; Edens \& Rosenheck, 2012; Kessler, et al., 2008; McIntyre, et al., 2007; Park, et al., 2011; Petry, et al., 2005).

Genetic risks for MDD and ADHD are of interest because prominent theoretical accounts posit that mood disturbance and impulsivity are important risk factors (Blaszczynski \& Nower, 2002; Sharpe, 2002). BD is the condition that shows the strongest association with DG in epidemiologic analyses of comorbidity (Kessler, et al., 2008, Petry, et al., 2005). SCZ has substantial genetic overlap with BD (Lichtenstein, et al., 2009; Purcell, et al., 2009). Polygenic risk for $\mathrm{BD}$ and $\mathrm{SCZ}$ are each related to a variety of substance use phenotypes (Carey, et al., 
2016; Hartz, et al., 2017; Reginsson, et al., 2017), suggesting they may influence multiple forms of addictive behaviors - possibly including DG.

\section{Materials and Methods}

\section{$\underline{\text { Participants }}$}

Participants were drawn from the National Longitudinal Study of Adolescent to Adult Health (Add Health; Harris, et al., 2009). The Add Health cohort is a nationally-representative United States sample that has been followed into young adulthood with four in-home interviews. Variables used were obtained in Wave IV $(\mathrm{N}=15,701$; response rate $=80 \%)$, which was conducted in 2008 when the participants were 24-34 years of age.

Procedure

Saliva samples were collected from consenting participants (96\%) during the Wave IV assessment. Consent for long-term archiving was obtained from approximately 12,200 (80\%) of those participants, making them eligible for genome-wide genotyping. Approximately $80 \%$ of the sample genotyping was performed with the Illumina Omni1-Quad BeadChip and 20\% was performed using the Illumina Omni2.5-Quad BeadChip. After quality control procedures, genotyped data were available for 9,974 individuals (7,917 from the Omni1 chip and 2,057 from the Omni2 chip) on 609,130 SNPs common across the two platforms (Braudt \& Harris, 2018; Highland, et al., 2018).

To account for population stratification, the genotyped sample was limited to the 9,129 individuals who could be assigned to one of four genetic ancestry groups based upon principal components analysis: European, African, Hispanic, and East Asian. Genetic ancestry was strongly correlated $(r=0.89)$ with self-identified race/ethnicity. The self-identified race/ethnicity of the 9,129 individuals was 5,754 (63\%) non-Hispanic white, 1,940 (21\%) non- 
Hispanic Black, 961 (11\%) Hispanic, 449 (5\%) Asian, and $23(<1 \%)$ Native American (Braudt \& Harris, 2018).

$\underline{\text { Measures }}$

Gambling and disordered gambling. The gambling assessment from the Add Health Wave IV interview included two questions: "Have you ever bought lottery tickets, played video games or slot machines for money, bet on horses or sporting events, or taken part in any other kinds of gambling for money?" and (if yes to the previous question) "Has your gambling ever caused serious financial problems or problems in your relationships with any of your family members or friends?" A dichotomous gambling phenotype was based on endorsing the first question, a dichotomous disordered gambling phenotype was based on endorsing the second.

Polygenic risk scores. Details regarding the construction of PRSs can be found in an Add Health technical report (Braudt \& Harris, 2018). Briefly, for a given PRS, each SNP was weighted by the regression coefficient for the corresponding SNP estimated in the discovery GWAS. These weighted effects were summed across all available variants (i.e., $p$-value threshold $=1.0$ ) to yield a single quantitative estimate of risk for the target condition attributable to common variants for each participant in the independent target sample. These calculations were performed using the PRSice wrapper for R within the PLINK package (Chang, et al., 2015). The PRS scores were then standardized within each ancestry group, yielding within-group PRSs with a mean of zero and a standard deviation of one.

The MDD PRS was based upon summary statistics from a genome-wide association meta-analysis involving 135,458 cases and 344,901 controls (Wray, et al., 2018). Owing to data sharing restrictions, the PRS for MDD were based on summary statistics that excluded 75,607 cases and 231,747 controls from the 23 andMe cohort. The ADHD score was calculated using 
statistics from a study of 20,183 cases and 35,191 controls (Demontis, et al., 2019). The BD PRS was based upon results from a study of 7,481 cases and 9,250 controls (Sklar, et al., 2011). The SCZ score used summary statistics from a GWAS investigation of 36,989 cases and 113,075 controls (Ripke, et al., 2014). No Add Health data were included in any of these discovery GWASs.

\section{$\underline{\text { Data Analysis }}$}

Data from close relatives were eliminated by retaining data from only a single member of each family. Because the discovery samples used to derive the PRSs were predominantly of European ancestry, analyses were restricted to individuals classified as having European ancestry according to the principal components analyses of genotyped SNPs. Together, these constraints yielded an analytic sample of 5,215 individuals.

Logistic regressions were conducted predicting gambling and disordered gambling. Analyses of DG were limited to individuals who endorsed lifetime gambling. Covariates were age, sex, and the first 10 ancestry principal components. For each model, the amount of variance in the phenotype accounted for by each PRS was estimated by computing the difference in Nagelkerke's pseudo- $R^{2}$ from a model that included both the covariate set and a particular PRS relative to a baseline model that included the covariates alone. This difference was multiplied by 100 to express it as a percentage of variance.

\section{Results}

Lifetime experience with gambling was reported by more than three quarters of the analytic sample $(78.4 \%, n=4,091)$. Table 1 summarizes results from 4 logistic regression analyses using individual PRSs to predict gambling endorsement. Surprisingly, higher polygenic risk for $\mathrm{BD}$ was associated with a significant reduction in the odds of gambling, $\mathrm{OR}=0.93,95 \%$ 
$\mathrm{CI}=0.87$ to $0.99, p=.045$, accounting for $0.12 \%$ of the variance. No other PRS was associated with gambling behavior.

DG was comparatively rare $(1.3 \%, n=70)$. Table 1 also summarizes results from models predicting endorsement of DG. Polygenic risk for SCZ was associated with significantly increased risk of DG, $\mathrm{OR}=1.54,95 \% \mathrm{CI}=1.07$ to $2.21, p=.020$, accounting for $0.85 \%$ of variance. Figure 1 illustrates this effect by plotting the odds ratios for DG as a function of SCZ PRS deciles, with the lowest decile as the reference category. This plot reveals that the effect was driven primarily by an increased risk of DG among those with the highest level of genetic risk for SCZ. Although not statistically significant, there was suggestive evidence of a possible association between $\mathrm{BD}$ risk and $\mathrm{DG}, \mathrm{OR}=1.24,95 \% \mathrm{CI}=0.97$ to $1.58, p=.082$, accounting for $0.47 \%$ of the variance. MDD and ADHD were not associated with DG.

In light of the similar effects for SCZ and BPD and the known genetic overlap between these conditions, we conducted an additional analysis predicting DG including both polygenic scores as predictors. The PRSs for SCZ and BPD were significantly correlated in the current sample, $r=0.28, p<.001$. In the simultaneous logistic regression, the pair of PRSs accounted for $0.98 \%$ of the variance. Neither PRS was nominally significant, but SCZ was associated with a comparatively stronger effect. The SCZ PRS (OR $=1.4495 \% \mathrm{CI}=0.97$ to $2.12, p=.07)$ accounted for an additional $.51 \%$ of variance relative to the model including BD alone. The BD score $(\mathrm{OR}=1.13,95 \% \mathrm{CI}=0.87$ to $1.48, p=.37)$ accounted for an additional $0.13 \%$ of variance in DG relative to a model including SCZ alone.

\section{Discussion}

The primary finding was that polygenic risk for SCZ was associated with DG in a nationally representative sample of young adults. This effect was small, accounting for $<1 \%$ of 
the variance in DG. However, this is comparable to the average effect size for the SCZ PRS in predicting other psychiatric disorders and traits and is actually stronger than its prediction of some SCZ-related features and outcomes (Bogdan, et al., 2018). This cross-disorder association suggests common genetic factors have pleiotropic effects on DG and SCZ. Theoretically, this might indicate that one disorder is an intermediate phenotype that provides a crucial link in the causal chain, setting conditions that may facilitate the acquisition of the second disorder. Under this scenario, SCZ could facilitate dysregulated gambling, or DG might increase risk for onset of SCZ. Although one could generate hypotheses about how such effects could occur, it seems unlikely that casual transactions involving the fully diagnosable clinical conditions explain the overlap. Instead, it seems more plausible that subtle, subclinical manifestations of genetic risk for SCZ increase risk for DG.

The current findings suggest that investigating features common to both SCZ and DG might generate valuable clues about the genetically-influenced liabilities to DG. Below, we speculate about some research domains that may merit closer scrutiny based on available evidence. Overlapping features that have been empirically associated with the SCZ PRS may represent especially interesting targets in light of the present findings.

Reduced cortical thickness has been observed in individuals with DG relative to healthy controls, a finding thought to be consistent with a diminished top-down control of impulsive behavior (Grant, et al., 2015). Reduced cortical thickness is also characteristic of individuals with BD and SCZ (Knöchel, et al., 2016; Rimol, et al., 2010), and the extent of this cortical thinning is correlated with the SCZ PRS (Neilson, et al., 2017). Interestingly, investigation of the genomic region most strongly associated with SCZ in the discovery GWAS (hence, producing the most heavily weighted effects in the SCZ PRS) implicates variations in the immune-related 
complement system that might result in excessive synaptic pruning and cortical thinning during adolescence and early adulthood (Sekar, et al., 2016). This pattern of evidence suggests additional work examining a potential role of cortical thinning in DG may be warranted.

Aberrant dopamine functioning has long been hypothesized to play a major role in the pathophysiology of SCZ (Howes, et al., 2016). Several lines of evidence also point to the involvement of dopaminergic mechanisms in DG (Nautiyal, et al., 2017, Zack \& Poulos, 2009). Compared to healthy controls, persons with DG show enhanced striatal dopamine release in response to an amphetamine challenge, and the magnitude of this effect is correlated with the severity of gambling problems (Boileau, et al., 2014). Pharmacologic manipulations of dopamine modulate motivation to gamble and the rewarding effects of gambling in problem gamblers (Zach \& Poulos, 2004; 2007), and treatment with dopamine agonists is associated with an increased risk of DG onset in patients with Parkinson's disease (Dagher \& Robbins, 2009; Dodd, et al., 2005). Some studies have found associations between dopamine-related candidate genes and gambling behaviors (e.g., Comings, et al., 1996; Gray \& MacKillop, 2014; Lobo, et al., 2015. A SNP associated with the $D R D 2$ gene was among the 108 genome-wide significant loci in the SCZ GWAS (Ripke, et al., 2014). However, there is limited evidence that the SCZ PRS is related to SCZ features thought to be dopamine-related, such as positive symptoms or antispsychotic dosage (Hettige, et al., 2016; Jones, et al., 2016; Sengupta, et al., 2017; Stepniak, et al., 2014). Furthermore, common genetic variants implicated in dopamine functioning do not collectively discriminate SCZ cases from controls (Edwards, et al., 2016). Thus, the polygenic liability shared by DG and SCZ might not prove to be strongly related to dopaminergic mechanisms. 
Relative to healthy controls, individuals with DG (Kovács, et al., 2017) and SCZ (Betz, et al., 2019; Woodrow, et al., 2018) exhibit impaired decision-making abilities on the Iowa Gambling Task (IGT; Bechara, et al., 1994). The IGT is a complex task that taps a multifaceted construct, and can reflect effects originating in a number of neural systems related to bottom-up impulsive processes and top-down reflective impulse control (Bechara, 2005; Buelow \& Suhr, 2009). Moreover, impaired performance on this task is seen in a wide variety of psychiatric and neurological patient populations (Mukherjee \& Kable, 2014). Thus, it is unclear whether the deficits observed in persons with DG and SCZ arise from a shared mechanism. There is some evidence that the common variant risk for SCZ is associated with risk-taking (Linnér, et al., 2019; Maxwell, et al., 2019) and that much of the association between the SCZ PRS and SCZ diagnosis is mediated by cognitive deficits (Toulopoulou, et al., 2019). However, no studies have specifically examined whether SCZ polygenic risk is related to performance on neuropsychological gambling tasks. Future research examining how the SCZ PRS is related to parameters of IGT behavioral responding and measures of the neural underpinnings of task performance could help to determine whether and how common genetic risk for SCZ might contribute to the impaired decision making, thereby potentially increasing risk for gambling problems.

Schizotypy is a multidimensional personality construct that is hypothesized to reflect subtle effects of genetic risk for SCZ (Meehl, 1990; Lenzenweger, 2006; Raine, 2006). Magical ideation, defined as belief in forms of causation that are invalid by conventional standards, is a trait associated with schizotypy (Eckblad \& Chapman, 1983). Magical ideation is similar to many of the superstitious beliefs and cognitive distortions characteristic of DG (Goodie \& Fortune, 2013; Tonneato, 1999; Leonard \& Williams, 2018; Zach \& Poulos, 2009). Magical 
ideation is elevated among gamblers, particularly those who prefer games of chance, such as lotteries and electronic gaming machines (Savage, et al., 2014). There is currently mixed evidence concerning an association between the SCZ PRS and measures of positive schizotypy or magical ideation (Hatzimanolis, et al., 2017; Isvoranu, et al., 2019; van Os, et al., 2017).

The SCZ PRS has been shown to be associated with various forms of substance use and dependence (Carey, et al., 2016; Hartz, et al., 2017; Regnisson, et al., 2017). The current findings extend this work, demonstrating that polygenic risk for $\mathrm{SCZ}$ associates with a behavioral addiction, DG, that is highly comorbid with substance use disorders in the general population (Kessler, et al., 2008; Petry, et al., 2005) and among individuals with psychosis (Fortgang, et al., 2018). Together, findings to date might indicate that common genetic risk for SCZ confers a general liability to impaired control over rewarding behaviors rather than modulating response to a particular drug or drug class. Alternatively, the findings are consistent with a process in which polygenic SCZ risk increases substance use, which may then serve as a mediator that causally influences downstream acquisition of DG.

Prominent theoretical accounts of DG etiology point to impulsivity and dysphoric mood as important liabilities (Blazczynski \& Nower, 2002; Sharpe, 2002). The SCZ PRS has been shown to be associated with negative symptoms, anxiety, depression, and externalizing traits and symptoms (Jansen, et al., 2017; Jones, et al., 2016; Nivard, et al., 2017; Riglin, et al., 2017; Sengupta, et al., 2017; van Os, et al., 2017). Thus, some of the theorized DG risk factors could conceivably arise from pleiotropic effects of genetic liability to SCZ.

Polygenic risk for $\mathrm{BD}$ was associated with decreased odds of ever having gambled. This finding was surprising because (a) diagnostic criteria for mania and hypomania include excessive involvement in pleasurable activities with a high potential for painful consequences, and (b) 
higher scores on the BD PRS were (nonsignificantly) associated with increased odds of DG. If this apparent protective effect of $\mathrm{BD}$ genetic risk on lifetime gambling proves replicable, more research will be needed to account for this puzzling finding ${ }^{1}$.

Several limitations should be considered. A simple two-item assessment was used to define lifetime gambling and DG status. Using formal diagnostic criteria or more nuanced multiitem screening instruments would have allowed us to probe whether particular clinical features of DG were associated with polygenic risk for various psychiatric disorders. Corrections for multiple testing were not used and the nominally significant effects in Table 1 would not remain if adjusted $p$-value thresholds were applied. This approach was adopted because (a) the current study was exploratory given the lack of available information concerning the molecular genetics of DG, and (b) the analyses also generated effect size estimates that can be directly compared to other studies. Nonetheless, there is clearly a need for replication of the current findings in independent samples. As expected in a general population survey, the prevalence of DG was low, limiting statistical power. Further investigation using clinical or case-control samples featuring more affected individuals would be informative. The PRSs were computed based on the $\sim 600,000$ markers shared across two genotyping arrays. Imputation to a reference panel prior to PRS calculation might have improved the precision of the computed scores. Add Health did not include assessments of psychosis, so we were not able to determine the prevalence of

\footnotetext{
${ }^{1}$ We considered the possibility that failure to control for educational attainment in the analysis could produce this effect. Lower educational attainment has been associated with increased odds of ever gambling (Kessler et al., 2008) and higher scores on the BD PRS have been associated with completing more years of schooling and attainment of a university degree (Power, et al., 2015). However, the association between BD PRS and lifetime gambling was essentially unchanged when controlling for either measured educational attainment or an educational attainment polygenic score (computed based upon Lee, et al., 2018).
} 
schizophrenia and related conditions. Thus, although we speculate that the findings are not attributable to DG being a direct cause or consequence of diagnosable schizophrenia spectrum disorders, these possibilities could not be ruled out empirically. The sample size of the discovery GWAS data set has implications for the predictive power of the PRS, with larger samples permitting more precise estimates of allelic effect sizes (Chatterjee, et al., 2013). The SCZ PRS has the highest estimated predictive power relative to polygenic scores for other psychiatric traits, in part owing to the massive sample size of the SCZ GWAS (So \& Sham, 2016). This may partly explain why a nominally significant association was only observed between DG and SCZ. In conclusion, our study indicates that genetic predisposition to $\mathrm{SCZ}$ is associated with increased risk of problematic gambling in young adulthood. Although replication studies are needed, the current finding provides new clues about the biological bases of DG. The SCZ PRS is being widely used in studies of various neurobehavioral domains. As evidence accumulates concerning the most robust correlates of polygenic risk for $\mathrm{SCZ}$, the nature of the specific mechanism(s) conferring risk for DG may become more evident. Multi-trait GWAS approaches that allow joint modeling of DG and SCZ might improve detection of DG-related loci and generate more informative PRSs for use in future research (Andreassen, et al., 2013; Turley, et al., 2018). 


\section{Acknowledgments}

Preparation of this article was supported in part by a Center of Excellence award from the National Center for Responsible Gaming.

This research uses data from Add Health, a program project directed by Kathleen Mullan Harris and designed by J. Richard Udry, Peter S. Bearman, and Kathleen Mullan Harris at the University of North Carolina at Chapel Hill, and funded by grant P01-HD31921 from the Eunice Kennedy Shriver National Institute of Child Health and Human Development, with cooperative funding from 23 other federal agencies and foundations. Special acknowledgment is due Ronald R. Rindfuss and Barbara Entwisle for assistance in the original design. Information on how to obtain the Add Health data files is available on the Add Health website (http://www.cpc.unc.edu/addhealth). No direct support was received from grant P01-HD31921 for this analysis. 


\section{References}

Andreassen, O. A., Thompson, W. K., Schork, A. J., Ripke, S., Mattingsdal, M., Kelsoe, J. R., ... \& Sklar, P. (2013). Improved detection of common variants associated with schizophrenia and bipolar disorder using pleiotropy-informed conditional false discovery rate. PLoS Genetics, 9, e1003455.

Bechara, A. (2005). Decision making, impulse control and loss of willpower to resist drugs: A neurocognitive perspective. Nature Neuroscience, 8, 1458-1463.

Bechara, A., Damasio, A.R., Samasio, H., \& Anderson, S.W. (1994). Insensitivity to future consequences following damage to human prefrontal cortex. Cognition, 50, 7-15.

Betz, L.T., Brambilla, P., Ilankovic, A., Prekumar, P., Kim, M-S., Raffard, S., Bayard, S., Hori, H., Lee, K-U., Lee, S.J., Koutsouleris, N., \& Kambeitz, J. (2019). Deciphering rewardbased decision-making in schizophrenia: A meta-analysis and behavioral modeling of the Iowa Gambling Task. Schizophrenia Research, 204, 7-15.

Blanco, C., Myers, J., \& Kendler, K. S. (2012). Gambling, disordered gambling and their association with major depression and substance use: a web-based cohort and twinsibling study. Psychological Medicine, 42(03), 497-508.

Blaszczynski, A., \& Nower, L. (2002). A pathways model of problem and pathological gambling. Addiction, 97, 487-499.

Bogdan, R., Baranger, D.A.A., \& Agrawal, A. (2018). Polygenic risk scores in clinical psychology: Bridging genomic risk to individual differences. Annual Review of Clinical Psychology, 14, 119-157.

Boileau, I., Payer, D., Chugani, B., Lobo, D.S.S., Houle, S., Wilson, A.A., Warsh, J., Kish, S.J., 
\& Zack, M. (2014). In vivo evidence for greater amphetamine-induced dopamine release in pathological gambling: a positron emission tomography study with [11 C]-(+)-PHNO. Molecular Psychiatry, 19, 1305-1313.

Braudt, D.B., \& Harris, K.M. (2018) Polygenic Scores (PGSs) in the National Longitudinal Study of Adolescent to Adult Health (Add Health) - Release 1. Available at https://www.cpc.unc.edu/projects/addhealth/documentation/guides/PGS AH1 UserGuid e.pdf

Buelow, M.T., \& Suhr, J.A. (2009). Construct validity of the Iowa Gambling Task. Neuropsychology Review, 19, 102-114.

Carey, C.E., Agrawal, A., Bucholz, K.K., Hartz, S.M., Lynskey, M.T., Nelson, E.C., Bierut, L.J., \& Bogdan, R. (2016). Associations between polygenic risk for psychiatric disorders and substance involvement. Frontiers in Genetics, 7, 149.

Chang, C. C., Chow, C. C., Tellier, L. C., Vattikuti, S., Purcell, S. M., \& Lee, J. J. (2015). Second-generation PLINK: rising to the challenge of larger and richer datasets. GigaScience, 4, 7.

Chatterjee, N., Wheeler, B., Sampson, J., Hartge, P., Chanock, S.J., \& Park, J-H. (2013). Projecting the performance of risk prediction based on polygenic analyses of genomewide association studies. Nature Genetics, 45, 400-405.

Clark, C., Nower, L., \& Walker, D. M. (2013). The relationship of ADHD symptoms to gambling behaviour in the USA: results from the National Longitudinal Study of Adolescent Health. International Gambling Studies, 13(1), 37-51.

Comings, D. E., Rosenthal, R. J., Lesieur, H. R., Rugle, L. J., Muhleman, D., Chiu, C., ... \& 
Gade, R. (1996). A study of the dopamine D2 receptor gene in pathological gambling. Pharmacogenetics, 6, 223-234.

Dagher, A. \& Robbins, T.W. (2009). Personality, addiction, dopamine: Insights from Parkinson's disease. Neuron, 61, 502-510.

Demontis, D., Walters, R. K., Martin, J., Mattheisen, M., Als, T. D., Agerbo, E., ... \& Cerrato, F. (2019). Discovery of the first genome-wide significant risk loci for attention deficit/hyperactivity disorder. Nature Genetics, 51, 63-75.

Dodd, M.L., Klos, K.J., Bower, J.H., Geda, Y.E., Josephs, K.A. \& Ahlskog, J.E. (2005). Pathological gambling caused by drugs used to treat Parkinson disease. Archives of Neurology, 62, 1377-1381.

Dudbridge, F. (2016). Polygenic epidemiology. Genetic Epidemiology, 40, 268-272.

Eckblad, M., \& Chapman, L.J. (1983). Magical ideation as an indicator of schizotypy. Journal of Consulting and Clinical Psychology, 51, 215-225.

Edens, E. L., \& Rosenheck, R. A. (2012). Rates and correlates of pathological gambling among VA mental health service users. Journal of Gambling Studies, 28(1), 1-11.

Edwards, A.C., Bacanu, S-A., Bigdelli, T.N., Mosczti, A., \& Kendler, K.S. (2016). Evaluating the dopamine hypothesis of schizophrenia in a large-scale genome-wide association study. Schizophrenia Research, 176, 136-140.

Fortgang, R.G., Hoff, R.A., \& Potenza, M.N. (2018). Problem and pathological gambling in schizophrenia: Exploring links with substance use and impulsivity. Journal of Gambling Studies, 34, 673-688.

Goodie, A.S. \& Fortune, E.E. (2013). Measuring cognitive distortions in pathological gambling: Review and meta-analysis. Psychology of Addictive Behaviors, 27, 730-743. 
Grant, J.E., Odlaug, B.L., \& Chamberlain, S.R. (2015). Reduced cortical thickness in gambling disorder: A morphometric MRI study. European Archives of Psychiatry and Clinical Neuroscience, 265, 655-661.

Gray, J. C., \& MacKillop, J. (2014). Genetic basis of delay discounting in frequent gamblers: examination of a priori candidates and exploration of a panel of dopamine-related loci. Brain and Behavior, 4, 812-821.

Harris K.M., Halpern C.T., Whitsel E., Hussey J., Tabor, J., Entzel P., et al. The National Longitudinal Study of Adolescent to Adult Health: Research Design. 2009; Available at: http://www.cpc.unc.edu/projects/addhealth/design.

Hartz, S.M., Horton, A.C., Oehlert, M., Carey, C.E., Agrawal, A., Bogdan, R., Chen, L-S, Hancock, D.B., Johnson, E.O., Pato, C.N., Patio, M.T., Rice, J.P., \& Bierut, L.J. (2017). Association between substance use disorder and polygenic liability to schizophrenia. Biological Psychiatry, 82, 709-715.

Hatzimanolis, A., Avramopoulos, DD., Arking, D.E., Moes, A., Bhatangar, P., Lencz, T., Malhorta, A.K., Giakoumaki, S.G., Roussos, P., Smyrnis, N., Bitsios, P., \& Stefanis, N.C. (2017). Stress-dependent association between polygenic risk for schizophrenia and schizoptypal traits in young army recruits. Schizophrenia Bulletin, 44, 223-347.

Hettige, N.C., Cole, C.B., Khalid, S., \& De Luca, V. (2016). Polygenic risk score prediction of antipsychotic dosage in schizophrenia. Schizophrenia Research, 170, 265-270.

Hodgins, D.C., Stea, J.N., \& Grant, J.E. (2011). Gambling disorders. Lancet, 378, 1874-1884.

Howes, O.D., McCutcheon, R., Owen, M.J., \& Murray, R.M. (2016). The role of genes, stress, and dopamine in the development of schizophrenia. Biological Psychiatry, 81, 9-20.

Highland, H.M., Avery, C. L., Duan, Q, Li, Y, \& Harris, K.M. (2018). Quality control analysis 
of Add Health GWAS Data. Available at:

https://www.cpc.unc.edu/projects/addhealth/documentation/guides/AH_GWAS_QC.pdf

Isvoranu, A. M., Guloksuz, S., Epskamp, S., van Os, J., Borsboom, D., \& GROUP Investigators. (2019, Epub). Toward incorporating genetic risk scores into symptom networks of psychosis. Psychological Medicine, 1-8. https://doi.org/10.1017/S003329171900045X

Jansen, P.R., Polderman, T.J.C., Bolhuis, K., van der Ende, J., Jaddoe, V.W.V., Verhulst, F.C., White, T., Posthuma, D., \& Tiemeier, H. (2017). Polygenic scores for schizophrenia and educational attainement are associated with behavioural problems in early childhood in the general population. The Journal of Child Psychology and Psychiatry, 59, 39-47.

Jones, H.J., Stergiakouli, E., Tansey, K.E., Hubbard, L., Heron, J., Cannon, M., Holmans, P., Lewis, G., Linden, D.E., Jones, P.B., Smith, G.D., O’Donovan, M.C., Owen, M.J., Walters, J.T., \& Zammit, S. (2016). Phenotypic manifestations of genetic risk for schizophrenia during adolescence in the general population. JAMA Psychiatry, 73, 221228.

Kessler, R.C., Hwang, I., LaBrie, R., Petukhova, M., Sampson, N.A., Winters, K.C., et al. (2008) DSM-IV pathological gambling in the National Comorbidity Survey Replication. Psychological Medicine, 38, 1351-1360.

Knöchel, C., Reuter, J., Reinke, B., Stäblein, M., Marbach, K., Feddern, R., Kuhlmann, K., Alves, G., Prvulovic, D., Wenzler, S., Linden, D.E.J., \& Oertel- Knöchel, V. (2016). Cortical thinning in bipolar disorder and schizophrenia. Schizophrenia Research, 172, 7885.

Kovács, I., Richman, M.J., Janka, Z., Maraz, A., \& Andó, B. (2017). Decision making measured 
by the Iowa Gambling Task in alcohol use disorder and gambling disorder: A systematic review and meta-analysis. Drug and Alcohol Dependence, 181, 152-161.

Lang M, Leménager T, Streit F, Fauth-Bühler M, Frank J, Juraeva D, .. \& \& Kiefer F (2016). Genome-wide association study of pathological gambling. European Psychiatry 36, 3846.

Lee, J. J., Wedow, R., Okbay, A., Kong, E., Maghzian, O., Zacher, M., ... \& Fontana, M. A. (2018). Gene discovery and polygenic prediction from a 1.1-million-person GWAS of educational attainment. Nature Genetics, 50, 1112-1121.

Lenzenweger, M.F. (2006). Schizotypy: An organizing framework for schizophrenia research. Current Directions in Psychological Science, 15, 162-166.

Leonard, C.A., \& Williams, R.J. (2018). Fallacious beliefs: Gambling specific and beliefs in the paranormal. Canadian Journal of Behavioural Science, 51, 1-11.

Li, E., Browne, M., Rawat, V., Langham, E., \& Rockloff, M. (2017). Breaking bad: Comparing gambling harms among gamblers and affected others. Journal of Gambling Studies, 33, 223-248.

Lichtenstein, P., Yip, B. H., Björk, C., Pawitan, Y., Cannon, T. D., Sullivan, P. F., \& Hultman, C. M. (2009). Common genetic determinants of schizophrenia and bipolar disorder in Swedish families: A population-based study. Lancet, 373, 234-239.

Lind, P.A., Zhu, G., Montgomery, G.W., Madden, P.A.F., Heath, A.C., Martin, N.G., \& Slutske, W.S. (2012). Genome-wide association study of a quantitative disordered gambling trait. Addiction Biology 18, 511-522.

Linnér, R. K., Biroli, P., Kong, E., Meddens, S. F. W., Wedow, R., Fontana, M. A., ... \& Nivard, 
M. G. (2019). Genome-wide association analyses of risk tolerance and risky behaviors in over 1 million individuals identify hundreds of loci and shared genetic influences. Nature Genetics, 51, 245-257.

Lobo, D. S., Aleksandrova, L., Knight, J., Casey, D. M., El-Guebaly, N., Nobrega, J. N., \& Kennedy, J. L. (2015). Addiction-related genes in gambling disorders: New insights from parallel human and pre-clinical models. Molecular Psychiatry, 20, 1002-1010.

Maier, R.M., Visscher, P.M., Robinson, M.R., \& Wray, N.R. (2018). Embracing polygenicity: a review of methods and tools for psychiatric genetics research. Psychological Medicine 48, 1055-1067.

Maxwell, J., Socrates, A., Glanville, K.P., Di Forti, M.D., Murray, R.M., Vassos, E., \& O’Reilly, P.F. (2019). Investigating the role of behaviour in the genetic risk for schizophrenia. BioRxiv, 611079.

McIntyre, R. S., McElroy, S. L., Konarski, J. Z., Soczynska, J. K., Wilkins, K., \& Kennedy, S. H. (2007). Problem gambling in bipolar disorder: results from the Canadian Community Health Survey. Journal of Affective Disorders, 102(1-3), 27-34.

Meehl, P.E. (1990). Toward an integrated theory of schizotaxia, schizotypy, and schizophrenia. Journal of Personality Disorders, 4, 1-99

Mukherjee, D., \& Kable, J.W. (2014). Value-based decision making in mental illness: A metaanalysis. Clinical Psychological Science, 2, 767-782.

Nautiyal, K. M., Okuda, M., Hen, R., \& Blanco, C. (2017). Gambling disorder: An integrative review of animal and human studies. Annals of the New York Academy of Sciences, 1394, 106-127.

Neilson, E., Bois, C., Gibson. J., Duff, B., Watson, A., Roberts, N., Brandon, N.J., Dunlop, J., 
Hall, J., McIntosh, A.M., Whalley, H.C., \& Lawrie, S.M. (2017). Effects of environmental risks and polygenic loading for schizophrenia on cortical thickness. Schizophrenia Research, 184, 128-136.

Nivard, M.G., Gage, S.H., Hottenga, J.J., van Beijsterveldt, C.E.M., Abdellaoui, A., Bartels, M., Baselmans, B.M.L., Ligthart, L., St. Pourcain, B., Boomsma, D.I., Munafó, M.R., \& Middeldorp, C.M. (2017). Genetic overlap between schizophrenia and developmental psychopathology: Longitudinal and multivariate polygenic risk prediction of common psychiatric traits during development. Schizophrenia Bulletin, 43, 1197-1207.

Park, S., Cho, M. J., Chang, S. M., Jeon, H. J., Cho, S. J., Kim, B. S., ... \& Hong, J. P. (2011). Prevalence, correlates, and comorbidities of adult ADHD symptoms in Korea: results of the Korean epidemiologic catchment area study. Psychiatry Research, 186(2-3), 378-383.

Petry, N.M., Stinson, F.S., \& Grant, B.F. (2005) Comorbidity of DSM-IV pathological gambling and other psychiatric disorders: Results from the National Epidemiologic Survey on Alcohol and Related Conditions. Journal of Clinical Psychiatry, 66, 564-574.

Potenza, M.N., Xian, H., Shah, K., Scherrer, J.F., \& Eisen, S.A. (2005) Shared genetic contributions to pathological gambling and major depression in men. Archives of General Psychiatry, 62, 1015-1021.

Power, R. A., Steinberg, S., Bjornsdottir, G., Rietveld, C. A., Abdellaoui, A., Nivard, M. M., ... \& Cesarini, D. (2015). Polygenic risk scores for schizophrenia and bipolar disorder predict creativity. Nature Neuroscience, 18, 953-955.

Purcell, S.M., Wray, N.R., Stone, J.L., Visscher, P.M., O’Donovan, N.C., Sullivan, P.F., Sklar, P., \& International Schizophrenia Consortium (2009). Common polygenic variation contributes to risk for schizophrenia and bipolar disorder. Nature, 460, 748-752. 
Raine, A. (2006). Schizotypal personality: Neurodevelopmental and psychosocial trajectories. Annual Review of Clinical Psychology, 2, 291-326.

Reginsson, G.W., Ingason, A., Eusden, J., Bjornsdottir, G., Olafsson, S., Sigurdsson, E., Oskarsson, H., Tyrfingsson, T., Runarsdottir, V., Hansdottir, I., Steinberg, S., Stefansson, H., Gudbjartsson, D.F., Thorgeirsson, T., \& Stefansson, K. (2017). Polygenic risk scores for schizophrenia and bipolar disorder associate with addiction. Addiction Biology, 23, 485-492.

Rimol, L.M., Hartberg, C.B., Nesvåg, R., Fennema-Notestine, C., Halger, D.J. Jr., Pung, C.J., Jennings, R.G., Haukvik, U.K., Lange, E., Nakstad, P.H., Melle, I., Andreasson, O.A., Dale, A.M., \& Agartz, I. (2010). Cortical thickness and subcortical volumes in schizophrenia and bipolar disorder. Biological Psychiatry, 68, 41-50.

Ripke, S., Neale, B. M., Corvin, A., Walters, J. T., Farh, K. H., Holmans, P. A., ... \& Pers, T. H. (2014). Biological insights from 108 schizophrenia-associated genetic loci. Nature, 511, 421-427.

Riglin, L., Collishaw, S., Richards, A., Thapar, A., Maughan, B., O’Donovan, M.C., \& Thapar, A. (2017). Schizophrenia risk alleles and neurodevelopmental outcomes in childhood: A population-based cohort study. Lancet Psychiatry, 1, 57-62.

Savage, J.E., Slutske, W.S., \& Martin, N.G. (2014). Personality and gambling involvement: A person-centered approach. Psychology of Addictive Behaviors, 28, 1198-1211.

Scherrer, J.F., Xian, H., Slutske, W.S., Eisen, S.A., \& Potenza, M.N. (2015). Associations between obsessive-compulsive classes and pathological gambling in a national cohort of male twins. JAMA Psychiatry, 72, 342-349.

Sekar, A., Bialas, A. R., de Rivera, H., Davis, A., Hammond, T. R., Kamitaki, N., ... \& 
Genovese, G. (2016). Schizophrenia risk from complex variation of complement component 4. Nature, 530, 177-183.

Sengupta, S.M., MacDonald, K., Fathalli, F., Yim, A., Lepage, M., Iyer, S., Malla, A., \& Joober, R. (2017). Polygenic risk score associated with specific symptom dimensions in firstepisode psychosis. Schizophrenia Research, 184, 116-121.

Sharpe, L. (2002). A reformulated cognitive-behavioral model of problem gambling: A biopsychosocial perspective. Clinical Psychology Review, 22, 1-25.

Sklar, P., Ripke, S., Scott, L. J., Andreassen, O. A., Cichon, S., Craddock, N., ... \& Corvin, A. (2011). Large-scale genome-wide association analysis of bipolar disorder identifies a new susceptibility locus near ODZ4. Nature Genetics, 43(10), 977-83.

Slutske, W.S. (2019). Genetic and environmental contributions to risk for disordered gambling. Gambling Disorder. A. Heinz, N. Romanczuk-Seiferth, \& M. Potenza, (eds.). Springer.

Slutske, W.S., Ellingson, J.M., Richmond-Rakerd, L.S., Zhu, G., \& Martin, N.G. (2013). Shared genetic vulnerability for disordered gambling and alcohol use disorder in men and women: Evidence from a national community-based Australian twin study. Twin Research and Human Genetics, 16, 525-34.

Slutske, W.S., Eisen, S.A., True, W.R., Lyons, M.J., Goldberg, J., \& Tsuang, M.T. (2000). Common genetic vulnerability for pathological gambling and alcohol dependence in men. Archives of General Psychiatry, 57, 666-73.

Slutske, W.S., Eisen, S.A., Xian, H., True, W.R., Lyons, M.J., Goldberg, J., \& Tsuang, M.T. (2001). A twin study of the association between pathological gambling and antisocial personality disorder. Journal of Abnormal Psychology, 110, 297-308.

So, H-C., \& Sham, P.C. (2016). Exploring the predictive power of polygenic scores derived from 
genome-wide association studies: A study of 10 complex traits. Bioinformatics, 33, 886892.

Stepniak, B., Papiol, S., Hammer, C., Ramin, A., Everts, S., Hennig, L., Begermann, M., \& Ehrenreich, H. (2014). Accumulated environmental risk determining age at schizophrenia onset" A deep phenotyping-based study. Lancet Psychiatry, 1, 444-453.

Sullivan, P.F., Agrawal, A., Bulik, C.M., Andreassen, O.A., Børglum, A.D., Breen, G., Cichon, S., Edenberg, H.J., Faraone, S.V., Gelertner, J., Matthews. C.A., Nievergelt. C.M., Smoller, J.W., O’Donovan, M.C. for the Psychiatric Genomics Consortium (2018). Psychiatric genomics: An update and an agenda. American Journal of Psychiatry 175, $15-27$.

Tonneatto, T. (1999). Cognitive psychopathology of problem gambling. Substance Use \& Misuse, 34, 1593-1604.

Toulopoulou, T., Zhang, X., Cherny, S., Dickinson, D., Berman, K.F., Straub, R.E., Sham, P., \& Weinberger, D.R. (2019). Polygenic risk score increases schizophrenia liability through cognition-relevant pathways. Brain, 142, 471-485.

Turley, P., Walters, R. K., Maghzian, O., Okbay, A., Lee, J. J., Fontana, M. A., ... \& Magnusson, P. (2018). Multi-trait analysis of genome-wide association summary statistics using MTAG. Nature Genetics, 50, 229-237.

van Os, J., van der Steen, Y., Islam, Md. A., Gülöksüz, S., Rutten, B.P., Simons, C.J., \& GROUP Investigators (2017). Evidence that polygenic risk for psychotic disorder is expressed in the domain of neurodevelopment, emotion regulation, and attribution of salience. Psychological Medicine, 47, 2421-2437.

Woodrow, A., Sparks, S., Bobrovskaia, V., Paterson, C., Murphy, P., \& Hutton, P. (2018). 
Decision-making ability in psychosis: A systematic review and meta-analysis of the magnitude, specificity, and correlates of impaired performance on the Iowa and Cambridge Gambling Tasks. Psychological Medicine, 49, 32-48.

Wray, N.R. et al. (2018). Genome-wide association analyses identify 44 risk variants and refine the genetic architecture of major depression. Nature Genetics, 50(5):668-81.

Xian, H., Giddens, J.L., Scherrer, J.F., Eisen, S.A., \& Potenza, M.N. (2014). Environmental factors selectively impact co-occurrence of problem/pathological gambling with specifc drug-use disorders in male twins. Addiction, 109, 635-44.

Zack, M., \& Poulos, C.X. (2004). Amphetamine primes motivation to gamble and gamblingrelated semantic networks in problem gamblers. Neuropsychopharmacology, 29, 195207.

Zack, M., \& Poulos, C.X. (2007). A D2 antagonist enhances the rewarding and priming effects of a gambling episode in pathological gamblers. Neuropsychopharmacology, 32, 16781686.

Zack, M., \& Poulos, C.X. (2009). Parallel roles for dopamine in pathological gambling and psychostimulant addiction. Current Drug Abuse Reviews, 2, 11-25. 
Table 1. Results from logistic regression models predicting gambling and disordered gambling.

\begin{tabular}{lccccccc}
\hline \multirow{2}{*}{$\begin{array}{c}\text { Polygenic Risk } \\
\text { Score }\end{array}$} & \multicolumn{3}{c}{ Any Gambling } & & \multicolumn{3}{c}{ Disordered Gambling } \\
\cline { 7 - 8 } \cline { 6 - 8 } & OR [95\% CI $]$ & $p$ & $\begin{array}{c}\text { Pseudo- } \\
R^{2}(\%)\end{array}$ & OR [95\% CI $]$ & $p$ & $\begin{array}{c}\text { Pseudo- } \\
R^{2}(\%)\end{array}$ \\
\hline Major Depression & $0.963[0.882,1.051]$ & .400 & .0009 & $1.078[0.786,1.476]$ & .642 & .0331 \\
ADHD & $0.994[0.930,1.063]$ & .868 & .0009 & $1.007[0.842,1.361]$ & .578 & .0160 \\
Bipolar Disorder & $0.934[0.874,0.999]$ & .045 & .1180 & $1.241[0.973,1.584]$ & .082 & .4671 \\
Schizophrenia & $0.942[0.853,1.040]$ & .233 & .0003 & $1.538[1.072,2.207]$ & .020 & .8481 \\
\hline
\end{tabular}




\section{Figure Legends}

Figure 1. Odds ratios and 95\% confidence intervals for deciles of schizophrenia polygenic risk score with the lowest decile serving as the reference category. 


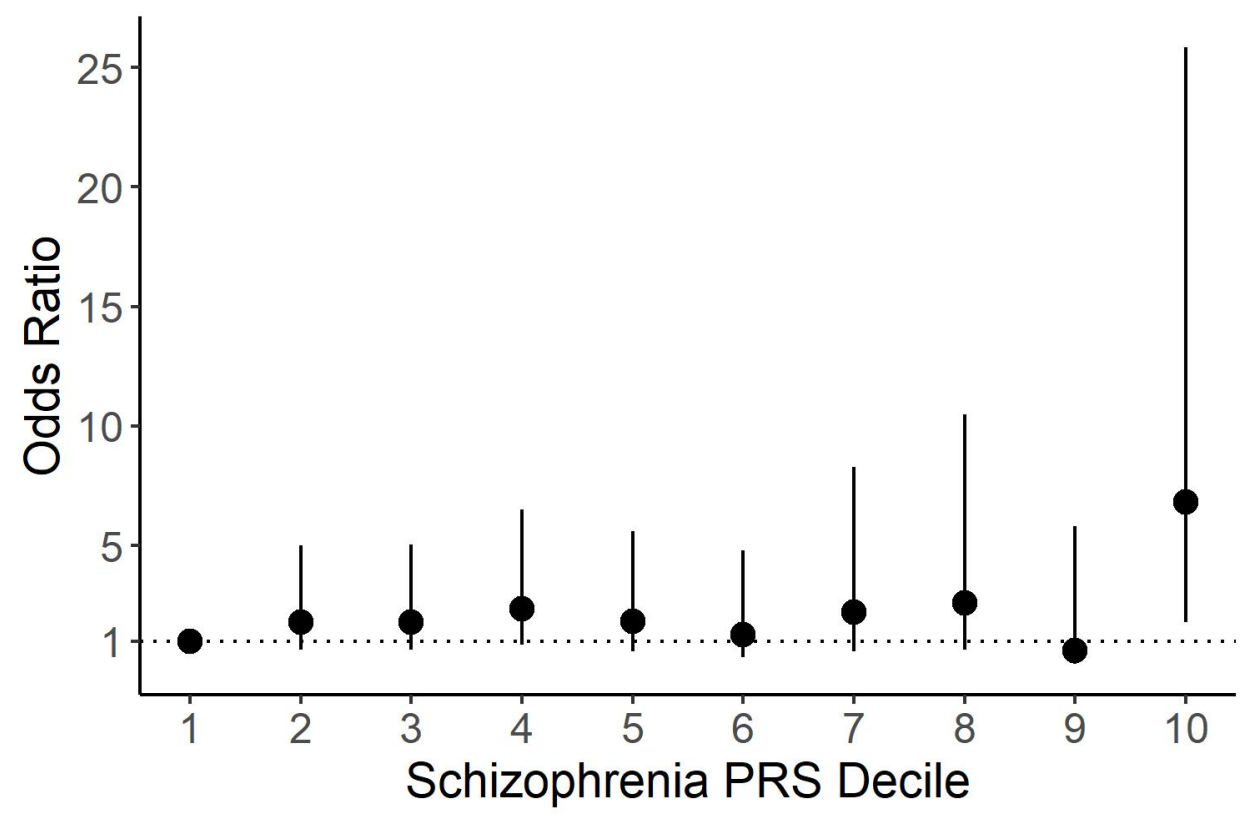

